\title{
A Synthetic Transcriptional Activator of Genes Associated with the Retina in Human Dermal Fibroblasts.
}

\section{AUTHOR(S):}

Syed, Junetha; Chandran, Anandhakumar; Pandian, Ganesh N; Taniguchi, Junichi; Sato, Shinsuke; Hashiya, Kaori; Kashiwazaki, Gengo; Bando, Toshikazu; Sugiyama, Hiroshi

\section{CITATION:}

Syed, Junetha ... [et al]. A Synthetic Transcriptional Activator of Genes Associated with the Retina in Human Dermal Fibroblasts.. Chembiochem 2015, 16(10): 1497-1501

\section{ISSUE DATE:}

2015-05-28

\section{URL:}

http://hdl.handle.net/2433/201619

\section{RIGHT:}

This is the peer reviewed version of the following article: Syed, J., Chandran, A., Pandian, G. N., Taniguchi, J., Sato, S. Hashiya, K., Kashiwazaki, G., Bando, T. and Sugiyama, H. (2015), A Synthetic Transcriptional Activator of Genes Associated with the Retina in Human Dermal Fibroblasts. ChemBioChem, 16: 1497-1501, which has been published in final form at http://dx.doi.org/10.1002/cbic.201500140. This article may be used for non-commercial purposes in accordance with Wiley Terms and Conditions for Self-Archiving.; The full-text file will be made open to the public on 28 May 2016 in accordance with publisher's 'Terms and Conditions for Self-Archiving'.; この論文は出版社版でありません 。引用の際には出版社版をご確認ご利用ください。; This is not the published version. Please cite only the published version. 


\title{
A Synthetic Transcriptional Activator of Genes Associated with Retina in Human Dermal Fibroblasts.
}

\author{
Junetha Syed ${ }^{[a]}$, Anandhakumar Chandran ${ }^{[a]}$, Ganesh N. Pandian ${ }^{[b]}$, Junichi Taniguchi ${ }^{[a]}$,Shinsuke \\ Sato $^{[b]}$, Kaori Hashiya ${ }^{[a]}$,Gengo Kashiwazaki ${ }^{[a]}$,Toshikazu Bando ${ }^{[a]}$ and Hiroshi Sugiyama* ${ }^{[a b]}$
}

\begin{abstract}
Developing small molecules capable of modulating epigenetic signatures can activate the transcription of tissuerestricted genes in a totally unrelated cell type and have potential use in epigenetic therapy. To provide an example of an initial approach, herein, we report on one synthetic small molecule termed 'SAHA-PIP X' from our library of conjugates, which triggered histone acetylation accompanied by the transcription of retinal tissue-related genes in human dermal fibroblasts.
\end{abstract}

The eukaryotic system harbors an organized pattern of tissue-specific gene expression, which is tightly regulated by a complex series of interactions between epigenetic factors and DNA sequences. Epigenetic regulation, including DNA methylation and histone modifications, controls the stepwise sequential activation of particular genes related to specific tissue development and related functions. ${ }^{[1]}$ Genes that are regulated in a tissue-specific fashion are thought to be surrounded by a specific chromatin environment in which the distribution of a high level of histone acetylation thereby triggers the active transcription of the respective genes. ${ }^{[2]}$

Small molecules can establish global changes in gene expression through histone acetylation by inhibiting the histone deacetylases (HDACs), a major subject of interest in finding ways to modify cell-fate decisions. Such molecules may have potential in the development of novel drugs to facilitate the reexpression of therapeutically important genes by rectifying defective epigenetic signatures. ${ }^{[3]}$ HDAC inhibitors such as suberoylanilide hydroxamic acid (SAHA) and trichostatin A are potential agents for epigenetic therapy. These agents may induce global histone acetylation, although their mode of action on the target is nonspecific. ${ }^{[4]}$ Defined control to regulate the gene expression induced by HDAC inhibitors can be achieved by providing a DNA-recognition motif comprising pyrroleimidazole polyamides (PIPs). When binding to their respective Watson-Crick base pairs, hairpin PIPs bind to the minor groove in DNA following a proposed DNA-pairing rule. ${ }^{[5]}$ Earlier studies have reported the development of sequence specific synthetic transcriptional activators by conjugating PIP with Activation domain of VP16 ${ }^{[6]}$ and nonpeptidic wrenchnolol. ${ }^{[7]}$

We have been successful in providing sequence specificity to the HDAC inhibitor SAHA by developing SAHA-PIP

[a] J.Syed, A. Chandran, J.Taniguchi, K. Hashiya, Dr. G.Kashiwazai, Dr. T.Bando, Prof. H. Sugiyama

Department of Chemistry, Graduate School of Science Kyoto University, Kitashirakawa-oiwakecho, Sakyo-ku, Kyoto 606-8502 (Japan)

E-mail: hs@kuchem.kyoto-u.ac.jp

[b] Dr. G. N. Pandian, S. Sato, Prof. H. Sugiyama Institute for Integrated Cell-Material Sciences (WPI-iCeMS) Kyoto University, Yoshida-ushinomiyacho, Sakyo-ku, Kyoto 606-8501 (Japan)

Supporting information for this article is given via a link at the end of the document. conjugates, and we have reported the targeted histone acetylation in the promoter region of $\mathrm{p} 16$, a tumor suppressor gene. ${ }^{\left[{ }^{8]}\right.}$ Because small molecules performing effective targetspecific gene activation will play a vital role in future therapeutics, we have developed a library of 32 SAHA-PIP conjugates A to $\varphi$ (numbered from 1 to 32 respectively). ${ }^{[9]}$ These have been designed such that each conjugate can recognize its unique sixbase-pair DNA sequence.

Initial studies on one such conjugate, termed SAHA-PIP K (also designated as SAHA-PIP 11) (Figure 1B), in somatic cells demonstrated its role in the activation of PIWI pathwayassociated genes responsible for germ cell lineage specification and gametogenesis. ${ }^{[3]}$ Further screening of our chemical library revealed the involvement of SAHA-PIP I (also designated as SAHA-PIP 9) in the induction of the core pluripotency gene network that remains silent in human fibroblasts. ${ }^{[10]}$ Moreover, SAHA or nonfunctional SAHA moiety covalently linked to PIP failed to activate the respective gene clusters thereby demonstrating the need of both active counterparts as conjugates in targeted transcriptional activation. ${ }^{[3,10]}$ We found that each SAHA-PIP conjugates possess an incredible ability as artificial transcriptional activator of unique silent gene circuits in cells, that may play distinct roles in the development and function of their respective tissues. ${ }^{[9]}$

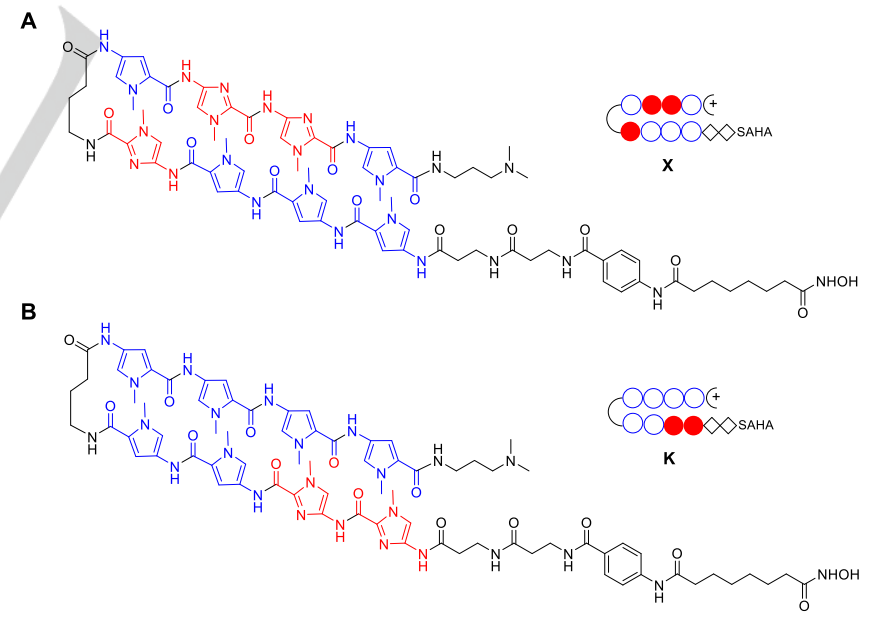

Figure 1. Chemical structure of the conjugates (A) SAHA-PIP $X$ and (B) SAHA-PIP K. Pyrrole and Imidazole are portrayed as open and closed circles respectively.

Retinal tissue is a part of the central nervous system that covers the inner surface of the eye and forms a vital part of the human visual system. In this sensory tissue, visual information in the form of light energy is encoded into electrical signals, which are then decoded by the brain as a complex visual image. ${ }^{[11]}$ Several ocular disorders can damage the morphology of the delicate layers of retinal tissue, resulting in varying degrees of irreversible vision loss. Once damaged, the retina cells cannot 
regenerate and are susceptible to a wide range of disorders such as retinal detachment, Usher syndrome, age-related macular degeneration (AMD), and retinitis pigmentosa (RP), an inherited retinal degenerative disease. Among the degenerative diseases, AMD and RP cause visual impairment affecting about 14 million and 1.5 million people worldwide, respectively. ${ }^{[12]}$

Table 1: Functional annotation of differentially regulated ophthalmic genes ( $\geq 2$ fold) in SAHA-PIP $X$ treated HDFs.

\begin{tabular}{|c|c|c|}
\hline Genes & $p$-Value ${ }^{a}$ & Ophthalmic disease ${ }^{b}$ \\
\hline $\begin{array}{l}\text { RARB, } \\
\text { STRA6 }\end{array}$ & 2.41E-04 & syndromic microphthalmia 9 \\
\hline $\begin{array}{l}\text { COL } 4 A 1 \\
\text { PAX6 }\end{array}$ & 3.47E-03 & anterior chamber malformation \\
\hline $\begin{array}{l}\text { PAX6, } \\
\text { RARB, } \\
\text { STRA6 }\end{array}$ & $7.42 \mathrm{E}-03$ & coloboma \\
\hline $\begin{array}{l}\text { PAX6, } \\
R A R B\end{array}$ & $9.98 \mathrm{E}-03$ & iris structural abnormality \\
\hline $\begin{array}{l}\text { CERKL, } \\
\text { USH2A }\end{array}$ & $1.43 \mathrm{E}-02$ & $\begin{array}{lll}\text { autosomal } & \text { recessive } & \text { retinitis } \\
\text { pigmentosa } & & \end{array}$ \\
\hline RS1 & $1.55 \mathrm{E}-02$ & X-linked retinoschisis \\
\hline PAX6 & $1.55 \mathrm{E}-02$ & $\begin{array}{l}\text { aniridia, cerebellar ataxia, and mental } \\
\text { retardation, bilateral optic nerve } \\
\text { aplasia, bilateral optic nerve } \\
\text { hypoplasia, congenital aniridia, foveal } \\
\text { hypoplasia and presenile cataract } \\
\text { syndrome, foveal hypoplasia with } \\
\text { anterior segment anomalies, } \\
\text { hereditary keratitis, morning glory } \\
\text { disc anomaly, }\end{array}$ \\
\hline CRYBB3 & $1.55 \mathrm{E}-02$ & $\begin{array}{l}\text { autosomal recessive congenital } \\
\text { nuclear cataract type } 2\end{array}$ \\
\hline COL4A1 & $1.55 \mathrm{E}-02$ & $\begin{array}{l}\text { brain small vessel disease with } \\
\text { Axenfeld-Rieger anomaly }\end{array}$ \\
\hline RIMS1 & $1.55 \mathrm{E}-02$ & cone-rod dystrophy 7 \\
\hline KERA & $1.55 \mathrm{E}-02$ & cornea plana 2 \\
\hline STRA6 & $1.55 \mathrm{E}-02$ & $\begin{array}{l}\text { isolated microphthalmia } \\
\text { coloboma } 8\end{array}$ \\
\hline LCN1 & $1.55 \mathrm{E}-02$ & $\begin{array}{l}\text { obstructive meibomian gland } \\
\text { dysfunction, seborrhoeic meibomian } \\
\text { gland dysfunction }\end{array}$ \\
\hline USH2A & $1.55 \mathrm{E}-02$ & retinitis pigmentosa type 39 \\
\hline $\begin{array}{l}\text { RS1, } \\
\text { SCN1A, } \\
\text { SCN5A }\end{array}$ & $1.82 \mathrm{E}-02$ & detachment of retina \\
\hline
\end{tabular}

a $p$-value corresponds to the probability of the focussed genes related with a specific biological annotation.

${ }^{\mathrm{b}}$ Ophthalmic disease resulted due to the defect in the corresponding gene.
Reports on the pathology of retinal degeneration have shown that several genetic components are responsible. For example, a defect in the gene CERKL, which regulates apoptosis in the retina, results in the progression of RP26. ${ }^{[13]} \mathrm{At}$ present, there are no medical treatments for many of these retinal disorders. Herein, we report the remarkable ability of SAHA-PIP X (also designated as SAHA-PIP 24) (Figure 1A) to activate visual system-specific genes in HDFs.

Whole-genome transcriptional profiling of human HDFs was performed using the Agilent SurePrint G3 Human GE v2 $8 \times 60 \mathrm{~K}$ Microarray platform after treatment with DMSO, SAHA, SAHA-PIP X $(1 \mu \mathrm{M})$ and SAHA-PIP $\mathrm{K}(1 \mu \mathrm{M})$ respectively for 48 h. ${ }^{[9]}$ Top disease and functional annotation of the normalized microarray data ( $\geq 2$-fold) of SAHA-PIP $X$ was performed by Ingenuity Pathway Analysis (IPA) to investigate its potential biological role. The analysis suggested the significant association of SAHA-PIP $X$ in regulating genes that fall into the ophthalmic disease category (Table S1).

Upon investigation of the SAHA-PIP $X$ induced ophthalmic disease network, revealed an array of potential ocular-specific therapeutic genes and their significance in providing resistance to the development of corresponding ocular disorders (Table 1). A heat map of these differentially expressed ophthalmic genes was constructed using the normalized probe-level intensity profiles from the microarray data of HDFs treated with DMSO, SAHA, SAHA-PIPs ( $K$ and $X)$. As a control, the expression profile of germ cell genes induced by SAHA-PIP $K^{[3]}$ is also included in the heat map to display the specificity of SAHA-PIP $X$ in up-regulating the ocular genes (Figure 2A). The result demonstrated clearly that SAHA-PIP $X$ specifically stimulated the ophthalmic-associated gene network in HDFs but not the germ cell genes, and the controls DMSO, SAHA, SAHA-PIP $K^{[3]}$ (germ cell switch) failed to regulate the ophthalmic gene network. To confirm this specific gene activation by SAHA-PIP X, we then performed qRT-PCR. Consistent with our microarray data, qRTPCR confirmed that SAHA-PIP $X$ activated the significant expression of ocular-specific genes such as PAX6, RS1, USH2A, CRYBB3, and STRA6 in HDFs. By contrast, the expression of these genes was not induced by the controls DMSO and SAHA (Figure 2B-2F).

The annotation represented in Table 1 shows clearly the pivotal role of SAHA-PIP $X$ in the regulation of retinal diseaseassociated genes. Knockout studies of genes such as Pax6 ${ }^{[14]}$, Stra6 ${ }^{[15]}$, Ush2a ${ }^{[16]}, C E R K L{ }^{[13]}$, and Rs $1^{[17,18]}$ have reported to display abnormal retina owing to the onset of dreadful retinal disorders.

Histone acetylation functions as a central switch that governs the conversion of repressive to permissive chromatin, which can facilitate the access of gene-regulatory sequences to the transcriptional machinery. ${ }^{[19]}$ Our previous reports on the SAHA-PIP conjugates $\mathrm{K}$ (germ cell switch) and I (pluripotency gene switch) have demonstrated a positive correlation between the induced expression and histone acetylation of the PIWI pathway ${ }^{[3]}$ and pluripotent ${ }^{[10]}$ genes respectively. Therefore, the observed effective induction of the retina -specific gene network 


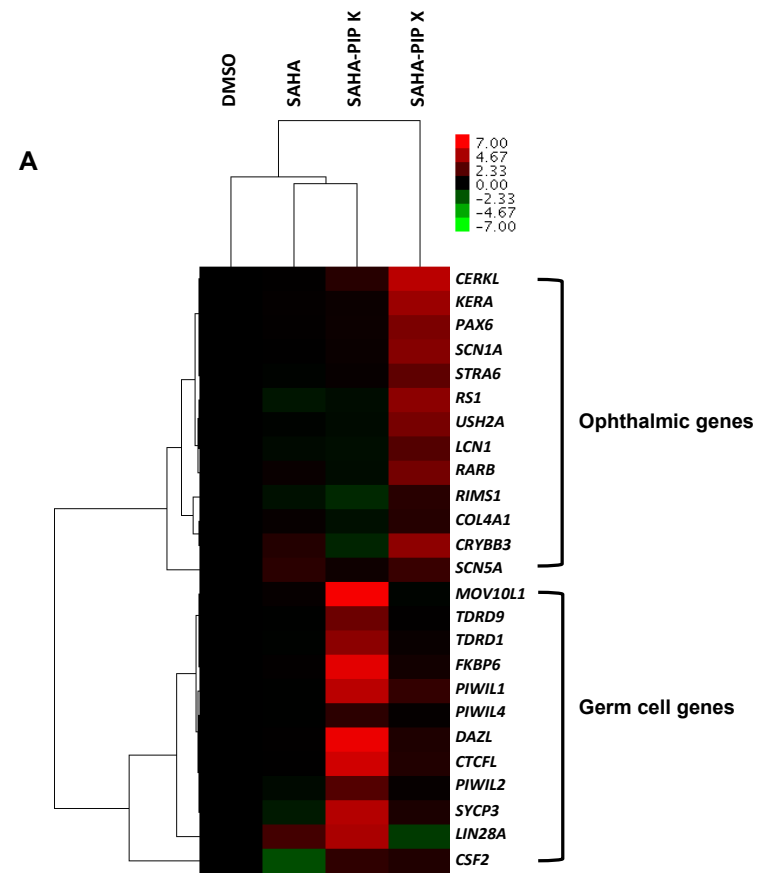

B $\quad P A X$

C
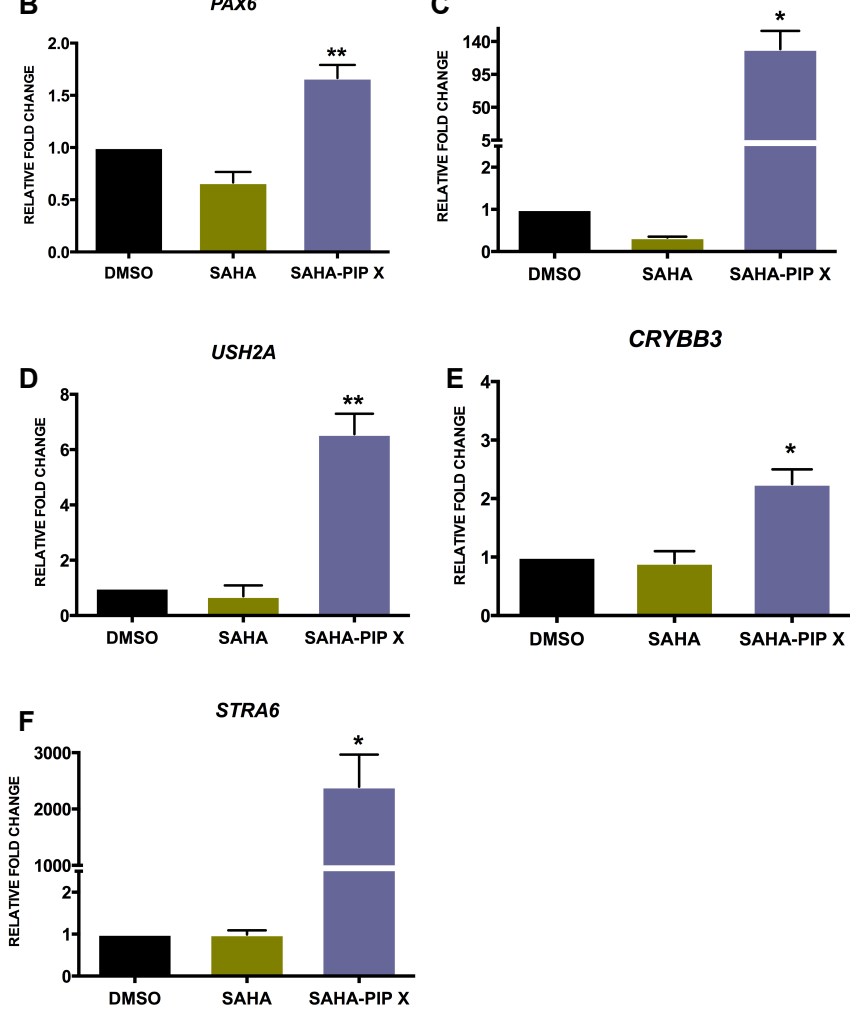

Figure 2. (A) Unsupervised hierarchical clustering of the selected ophthalmic genes and germ cell genes among DMSO, SAHA, SAHA-PIPs $K$ and $X$ treated HDFs. Heat map depicts the differential expression profile of genes in $\log 2$ ratio as indicated in the colorbar. Data presented here are cumulative of triplicates. Quantification of the mRNA level of genes (B) PAX6, (C) RS1, (D) USH2A, (E) CRYBB3 and (F) STRA6 in DMSO (0.5\%), SAHA and SAHA-PIP $X$ treated HDFs. $q-R T$ PCR data represents mean \pm SEM. $\left(^{*}\right) P$ value $<0.05$ and $\left(^{* *}\right) P$ value $<0.01$ by SAHA-PIP $X$ should be complemented by potential histone acetylation at the epigenome level in HDFs.

H3K27 acetylation is one of the overrepresented histone marks found in the active enhancer and promoter regions of genes associated with retinal cells. ${ }^{[20]}$ Increased histone acetylation around the gene body with low acetylation before SAHA-PIP treatment is likely to be associated with the HDAC inhibition surrounding the respective gene region and active transcription. Therefore, We next performed ChIP-seq to evaluate the H3K27ac occupancy on SAHA-PIP $X$ induced retinal genes in HDFs. Effective H3K27 acetylation (H3K27ac) were observed along the up-regulated retina genes such as $P A X 6$, and CERKL (Figure $3 \mathrm{~A}-3 \mathrm{~B}$ ) in SAHA-PIP $\mathrm{X}$ treated HDFs compared with DMSO-treated HDFs. Conversely, histone acetylation were not obtained along the control germ cellspecific MOV10L1 (Figure 3C) in SAHA-PIP X treated samples. Next, we screened around transcription start site of the regulated retinal genes for the potential SAHA-PIP $X$ binding site (5'-WCGGWW-3'). The frequency of the SAHA-PIP $X$ binding site is relatively higher around the histone-acetylated regions in the retina-specific genes than the control germ cell gene MOV10L1 (Figure 3A-3C). The above observations support the distinctiveness of each SAHA-PIP conjugate in activating its unique cluster of regulatory genes.

The ChIP-seq data for other imperative retinal genes such as COL4A1, USH2A, and SCN1A (Figure S1A-S1C) in SAHAPIP $X$ treated HDFs and their corresponding regions showing H3K27 acetylation (Table S2) is provided in the supplementary information. The peak annotation (Table S2) demonstrates that the histone acetylation was obtained in the functionally important regulatory promoter and also in the intergenic regions of the analyzed retinal genes.

Furthermore, we performed HOMER motif analysis with ChIP-seq acetylation peaks to identify the possible genomic site recognized by SAHA-PIP X. ${ }^{[21]}$ The highly significantly enriched motif from the above mentioned analysis closely resembles the potential binding site for SAHA-PIP X (5'-WCGGWW-3') (Figure 3D and Table S3). These observations suggest the possibility of sequence specific SAHA-PIP $X$ binding, leads to the active histone acetylation and probable gene activation.

Epigenetic modifications such as histone acetylation play an important role in regulating appropriate gene expression that aids in the proper functioning of the retina without any complications. [4] However, histone deacetylases such as HDAC2 and HDAC3 have been reported to induce the death of retinal ganglion cells (RGC) by inhibiting the expression of crucial RGC genes. ${ }^{[4,22]}$ Several nonspecific HDAC inhibitors (e.g., sodium butyrate, valproic acid ${ }^{[4,23]}$ and trichostatin $A^{[24]}$ ) have indicated positive effect by shielding the retina against disorders. However, the application of HDAC inhibitors in treating retinal diseases has disadvantages in terms of selectivity as they modify histones at a global level causing detrimental side effects. Achieving selective gene activation without disturbing the undesirable histone marks is one of the 
Chr 11: 31830 kb - 31840 kb

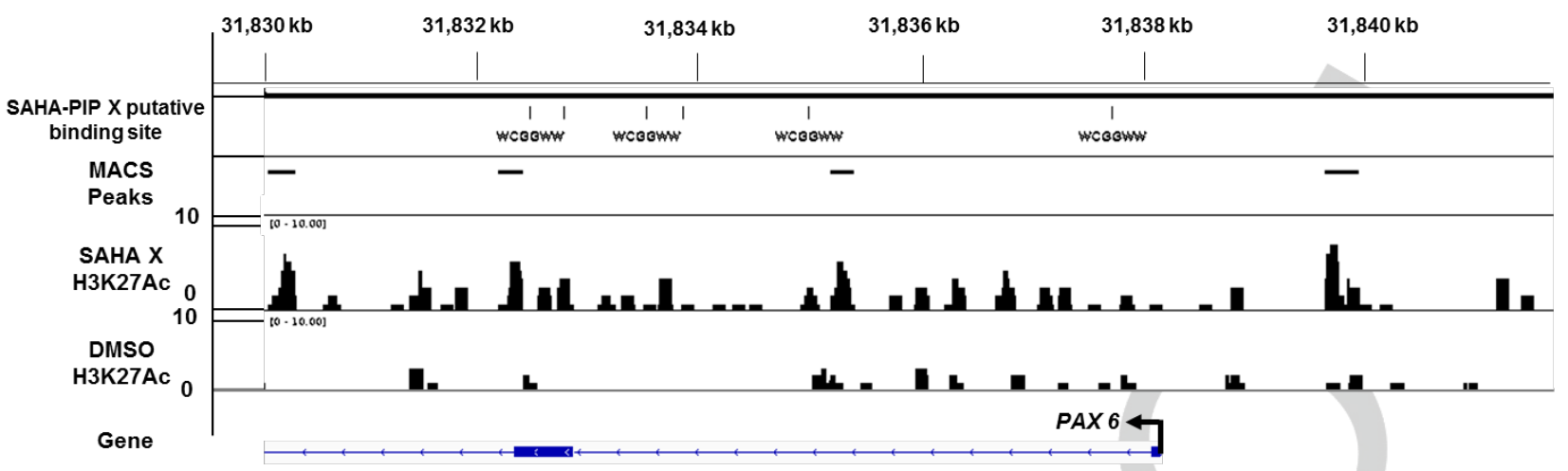

B Chr 2: $182,510 \mathrm{~kb}-182,530 \mathrm{~kb}$

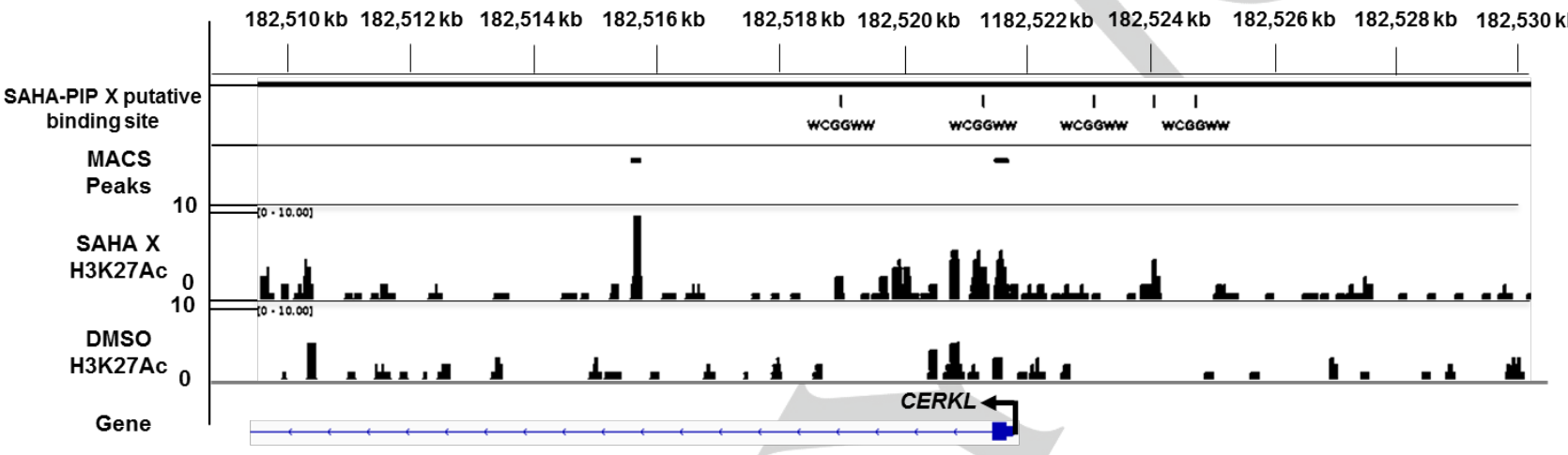

C

Chr 22: 50,526 kb $-50,534$ kb

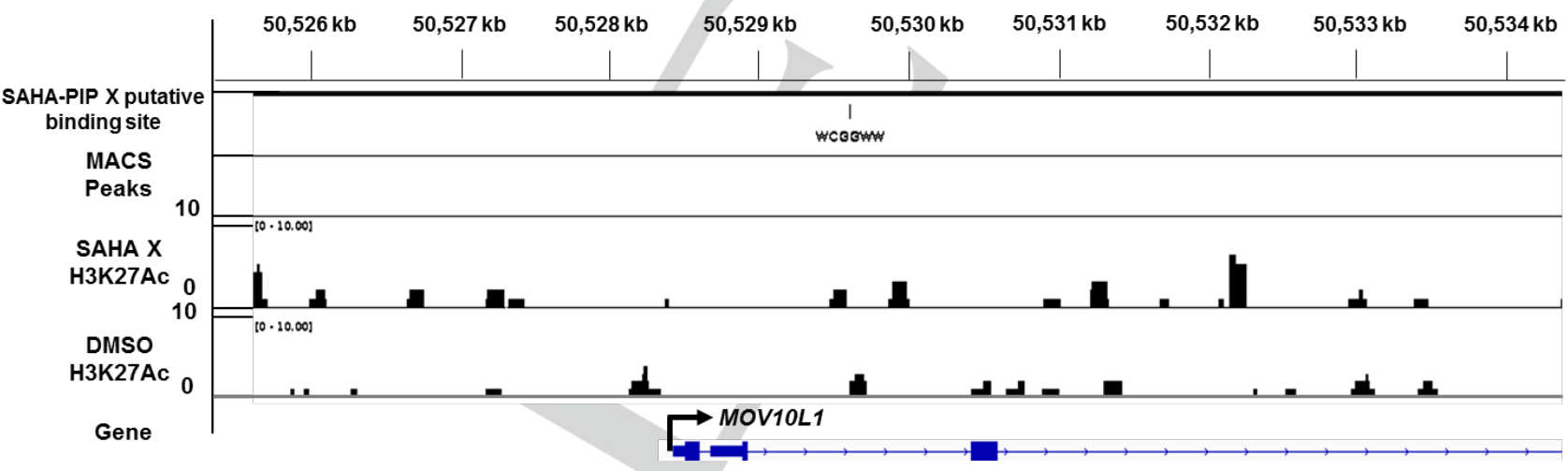

D

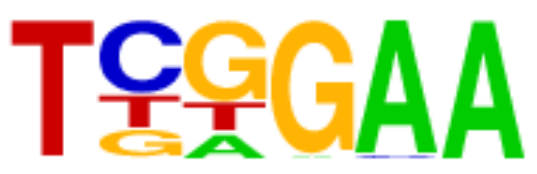

Figure 3. ChIP-seq results demonstrating the relative distribution of H3K27 acetylation abundance in the promoter region and the gene body of A) PAX6, B) CERKL C) and the control MOV10L1 respectively in DMSO and SAHA-PIP X treated HDF cells. IgG is used as an antibody control. The H3K27 acetylated peak calling was performed using MACS 1.4.2 in DMSO and SAHA-PIP $X$ treated samples in terms with their respective IgG control. The obtained MACS peak revealed the enhanced H3K27 acetylation by SAHA-PIP X in retinal related genes relative to those in the control DMSO-treated cells. The track representing the SAHA-PIP X putative binding site displays the frequency of match binding site 5'-WCGGWW-3' along the gene body. (D) Significant motif ( $p$ value 1e-112) from the ChIP-seq peaks matching the binding site of SAHA-PIP X (5'-WCGGWW-3') as determined by HOMER software. 
aims in the development of small molecules that could be of use in treating retinal or any other dreadful disorders. In this context, we are pursuing the development of library of potent artificial transcriptional activators (SAHA-PIP) composed of two units; SAHA, a HDAC inhibitor and cell permeable pyrrole- imidazole polyamide that can bind to sequence-specific target DNA. This study describes one of our small molecules SAHA-PIP $X$ that displayed quite a significant sequence specificity in activating the therapeutically important retinal genes by histone modification as observed by ChIP-seq in HDFs. Our future studies will be aiming towards the elucidation of mechanism and optimizing the structure of SAHA-PIP $X$ in improving its specificity to the retinal gene circuits by mapping its interaction ${ }^{[25]}$ across the human genome by Chem-seq. In addition, better understanding of the cell type behavior and pharmacokinetic properties of SAHA-PIP $X$ will be helpful in using our strategy for possible therapeutic applications.

\section{Acknowledgements}

This work was supported by Ministry of Education, Culture, Sports, Science and Technology (MEXT) of Japan, administrated by the Japan Society for the Promotion of Science. Junetha Syed and Anandhakumar Chandran are thankful to Japan Educational Exchange and Services (JEES) and Mitsubishi Corporation for supporting with scholarship.
[15] J. Amengual, N. Zhang, M. Kemerer, T. Maeda, K. Palczewski, J. Von Lintig, Hum. Mol. Genet. 2014, 4, 1-16.

[16] E. Aller, A. V. Sánchez-Sánchez, J. U. Chicote, G. García-García, P. Udaondo, L. Cavallé, M. Piquer-Gil, A. García-España, M. Díaz-Llopis, J. M. Millán, et al., PLoS One. 2013, 8, DOI 10.1371/journal.pone.0074995.

[17] Y. Takada, C. Vijayasarathy, Y. Zeng, S. Kjellstrom, R. A. Bush, P. A. Sieving, Investig. Ophthalmol. Vis. Sci. 2008, 49, 3677-3686.

[18] G. Luna, S. Kjellstrom, M. R. Verardo, G. P. Lewis, J. Byun, P. A. Sieving, S. K. Fisher, Investig. Ophthalmol. Vis. Sci. 2009, 50, 39773984

[19] A. Eberharter, P. B. Becker, EMBO Rep. 2002, 3, 224-229.

[20] A. K. Hennig, G. H. Peng, S. Chen, PLoS One 2013, 8, DOI 10.1371/journal.pone.0069721.

[21] S. Heinz, C. Benner, N. Spann, E. Bertolino, Y. C. Lin, P. Laslo, J. X. Cheng, C. Murre, H. Singh, C. K. Glass, Mol. Cell 2010, 38, 576-589.

[22] H. R. Pelzel, C. L. Schlamp, R. W. Nickells, BMC Neurosci. 2010, 11, 62.

[23] J. Biermann, J. Boyle, A. Pielen, W. A. Lagrèze, Mol. Vis. 2011, 17, 395-403.

[24] C. E. Crosson, S. K. Mani, S. Husain, O. Alsarraf, D. R. Menick, Investig. Ophthalmol. Vis. Sci. 2010, 51, 3639-3645.

[25] G. S. Erwin, D. Bhimsaria, A. Eguchi, A. Z. Ansari, Angew. Chemie - Int. Ed. 2014, DOI 10.1002/anie.201405497.

Keywords: artificial transcription activator - sequence recognition • Histone acetylation $\cdot$ Transcription profiling $\bullet$ ChIP

[1] C.-T. Ong, V. G. Corces, Nat. Rev. Genet. 2011, 12, 283-293.

[2] E. C. Forsberg, K. M. Downs, H. M. Christensen, H. Im, P. A. Nuzzi, E. H. Bresnick, Proc. Natl. Acad. Sci. U. S. A. 2000, 97, 14494-14499.

[3] L. Han, G. N. Pandian, S. Junetha, S. Sato, C. Anandhakumar, J. Taniguchi, A. Saha, T. Bando, H. Nagase, H. Sugiyama, Angew. Chem. Int. Ed. Engl. 2013, 52, 13410-13413.

[4] R. C. Rao, A. K. Hennig, M. T. A. Malik, D. F. Chen, S. Chen, J. Ocul. Biol. Dis. Infor. 2011, 4, 121-136.

[5] J. S. Kang, J. L. Meier, P. B. Dervan, J. Am. Chem. Soc. 2014, 136, 3687-3694.

[6] A. Z. Ansari, A. K. Mapp, D. H. Nguyen, P. B. Dervan, M. Ptashne, Chem. Biol. 2001, 8, 583-592.

[7] Y. Kwon, H. D. Arndt, Q. Mao, Y. Choi, Y. Kawazoe, P. B. Dervan, M. Uesugi, J. Am. Chem. Soc. 2004, 126, 15940-15941.

[8] A. Ohtsuki, M. T. Kimura, M. Minoshima, T. Suzuki, M. Ikeda, T. Bando, H. Nagase, K. Shinohara, H. Sugiyama, Tetrahedron Lett. 2009, 50, 7288-7292.

[9] G. N. Pandian, J. Taniguchi, S. Junetha, S. Sato, L. Han, A. Saha, C AnandhaKumar, T. Bando, H. Nagase, T. Vaijayanthi, et al., Sci. Rep. 2014, 4, 3843

[10] G. N. Pandian, S. Sato, C. Anandhakumar, J. Taniguchi, K. Takashima, S. Junetha, L. Han, A. Saha, T. Bando, H. Nagase, et al., ACS Chem.Biol. DOI: $10.1021 / \mathrm{cb} 500724 \mathrm{t}$

[11] N. Cuenca, L. Fernández-Sánchez, L. Campello, V. Maneu, P. De la Villa, P. Lax, I. Pinilla, Prog. Retin. Eye Res. 2014, 43, 17-75.

[12] Y. Huang, V. Enzmann, S. T. Ildstad, Stem Cell Rev. Reports 2011, 7, 434-445.

[13] M. Riera, D. Burguera, J. Garcia-Fernàndez, R. Gonzàlez-Duarte, PLoS One. 2013, 8, DOI 10.1371/journal.pone.0064048.

[14] R. Quiring, U. Walldorf, U. Kloter, W. J. Gehring, Science 1994, 265, 785-789. 
WILEY-VCH

\section{COMMUNICATION}
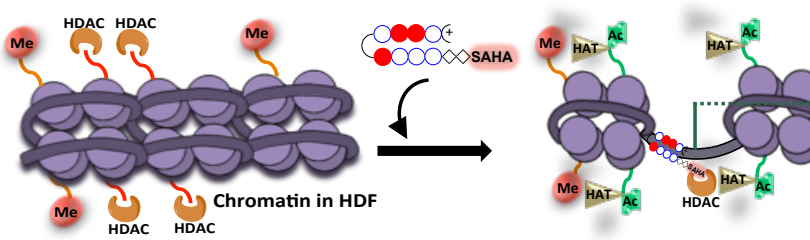

Artificial retinal gene switch: Dynamics of histone acetylation and deacetylation governs the complex mechanism of tissue specific gene expression. Our present work demonstrates the notable ability of the conjugate SAHA-PIP X, in inducing the transcription of therapeutically important retinal genes in HDF by histone modifications. SAHA-PIP $X$ enhanced H3K27 acetylation occupancy along specific retinal genes and ChIP-seq peaks exhibited enrichment of motif corresponding the SAHA-PIP $X$ binding site.
J. Syed, C. Anandhakumar, G. N. Pandian, J. Taniguchi, S. Sato, K.Hashiya, G. Kashiwazaki,T. Bando and H. Sugiyama*

\section{Page No. - Page No.}

A Synthetic Transcriptional Activator of Genes Associated with Retina in Human Dermal Fibroblasts. 